\title{
Community Structure of Hermatypic Corals at French Frigate Shoals, Northwestern Hawaiian Islands: Capacity for Resistance and Resilience to Selective Stressors ${ }^{1}$
}

\author{
Fean C. Kenyon, ${ }^{2,4}$ Peter S. Vroom,$^{2}$ Kimberly N. Page, ${ }^{2}$ Matthew 7. Dunlap, ${ }^{2}$ \\ Casey B. Wilkinson, ${ }^{2}$ and Greta S. Aeby ${ }^{3}$
}

\begin{abstract}
Georeferenced towed-diver surveys covering more than 100,000 $\mathrm{m}^{2}$ of benthic habitat and site-specific surveys at 30 sites during 2000-2002 determined distribution and abundance of scleractinian corals at French Frigate Shoals (FFS), Northwestern Hawaiian Islands. Percentage cover of corals was quantified by genus or species in forereef, backreef, and lagoon habitats and at La Perouse Pinnacles using three complementary methods: towed-diver surveys, video transects, and photoquadrats. Habitat-specific colony density and size-class distributions from measurements made within belt transects at fixed sites indicated that three coral genera, Porites, Pocillopora, and Acropora, accounted for more than $93 \%$ of total coral cover throughout the atoll, and their relative percentage cover, densities, and size distributions varied according to habitat and geographic location within the atoll. These descriptive data, which provide the most comprehensive overview yet of the scleractinian coral community at FFS, were used to assess the coral reefs' potential for resistance and resilience to selective stressors including bleaching, disease, and Acanthaster outbreaks. They also serve as a baseline for an ecosystem-based, long-term monitoring program with an objective of linking coral community change to other biological and physical factors.
\end{abstract}

Worldwide, coral reEFs are in decline from multiple anthropogenic stressors (Gardner et al. 2003, Hughes et al. 2003, Bellwood et al. 2004, Palumbi 2005, Pandolfi et al.

${ }^{1}$ This work is part of an interdisciplinary effort by the NOAA Pacific Islands Fisheries Science Center Coral Reef Ecosystem Division to assess and monitor coral reef ecosystems in the U.S. Pacific. Funding from the Office of Habitat Conservation at NOAA Fisheries, facilitated by Tom Hourigan as part of NOAA's Coral Reef Conservation Program, and the NWHI Coral Reef Ecosystem Reserve, facilitated by Robert Smith, supported this work. Manuscript accepted 19 May 2005.

${ }^{2}$ Joint Institute for Marine and Atmospheric Research, University of Hawai'i, 1125B Ala Moana Boulevard, Honolulu, Hawai'i 96814.

${ }^{3}$ Hawai'i Department of Land and Natural Resources, Division of Aquatic Resources, 1151 Punchbowl Street, Honolulu, Hawai'i 96813.

${ }^{4}$ Corresponding author (phone: 808-592-7019; fax: 808-592-7013; e-mail: Jean.Kenyon@noaa.gov).

Pacific Science (2006), vol. 60, no. 2:153-175

(C) 2006 by University of Hawai'i Press

All rights reserved
2005). In response to reef degradation, scientists and managers are exploring the concept of identifying reef areas that are naturally resistant to stressors and where conditions are likely to promote recovery from stressorinduced damage. Focusing on mass coral bleaching as a stress response to high sea surface temperatures and solar radiation, West and Salm (2003) defined "resistance" as the ability of individual corals to resist bleaching or to survive after they have been bleached. Reef "resilience" was defined by those authors as the ability to return to a previous state of diversity and abundance through growth and reproduction of surviving corals and through successful larval recruitment. Other authors (e.g., McClanahan et al. 2002, Hughes et al. 2003) also use the term "resilience" to denote the ability of coral reefs to recover from natural or anthropogenic disturbance. Viewed by Nystöm et al. (2000) within the context of nonequilibrium environments with multiple stable states, "resilience" includes the magnitude of disturbance that can 




FIgUre 1. The Hawaiian Archipelago. NWHI, Northwestern Hawaiian Islands; MHI, main Hawaiian Islands. Lightly shaded areas represent 100-fathom (183-m) isobaths.

be absorbed by a system before it shifts from one stable state to another and therefore incorporates the ability to resist disturbance. Identifying reefs that are likely to sustain little damage in response to stressors or to recover from the effects of stressors requires knowing coral species composition, population parameters, and variation among habitats in the absence of extreme disturbance (Bak and Meesters 1999). Knowledge of species' responses to stressors such as bleaching, predator outbreaks, disease, sedimentation, and pollution, coupled with available information on larval dispersal and recruitment, can then assist in evaluating the reef's vulnerability and capacity to recover from damage. Although such characterizations are essentially descriptive in nature, they are a necessary first step in identifying potential areas of resistance and resilience in a world where pristine coral reefs no longer exist (Hughes et al. 2003, Pandolfi et al. 2003).

The Northwestern Hawaiian Islands (NWHI) are a chain of small rocky islands, atolls, coral islands, and reefs that span $\sim 1,800 \mathrm{~km}$ over more than five degrees of latitude in the northwestern portion of the Hawaiian Archipelago (Figure 1). French Frigate Shoals (FFS) is the remnant portion of a crescent-shaped atoll approximately 27 $\mathrm{km}$ in length (NOAA 2003), with a wellformed barrier reef and lagoon (Figure 2). A small vestige of basalt, La Perouse Pinnacles, extends above sea level in the interior of the lagoon. The atoll supports the widest range of reef habitats in the Hawaiian Archipelago because of the presence of both atoll and basalt features (Grigg and Dollar 1980, Maragos and Gulko 2002). Limited research was conducted on marine species in the NWHI before the early 1970s. In 1977 several federal and state agencies collaborated in a five-year survey and assessment of marine resources to protect unique wildlife and fishery resources (Grigg and Tanoue 1984). Quantitative surveys of coral communities at FFS accomplished through this multiagency partnership were conducted exclusively along southwestern seaward reefs (Grigg 1983).

In 2000, benthic marine ecosystems be- 


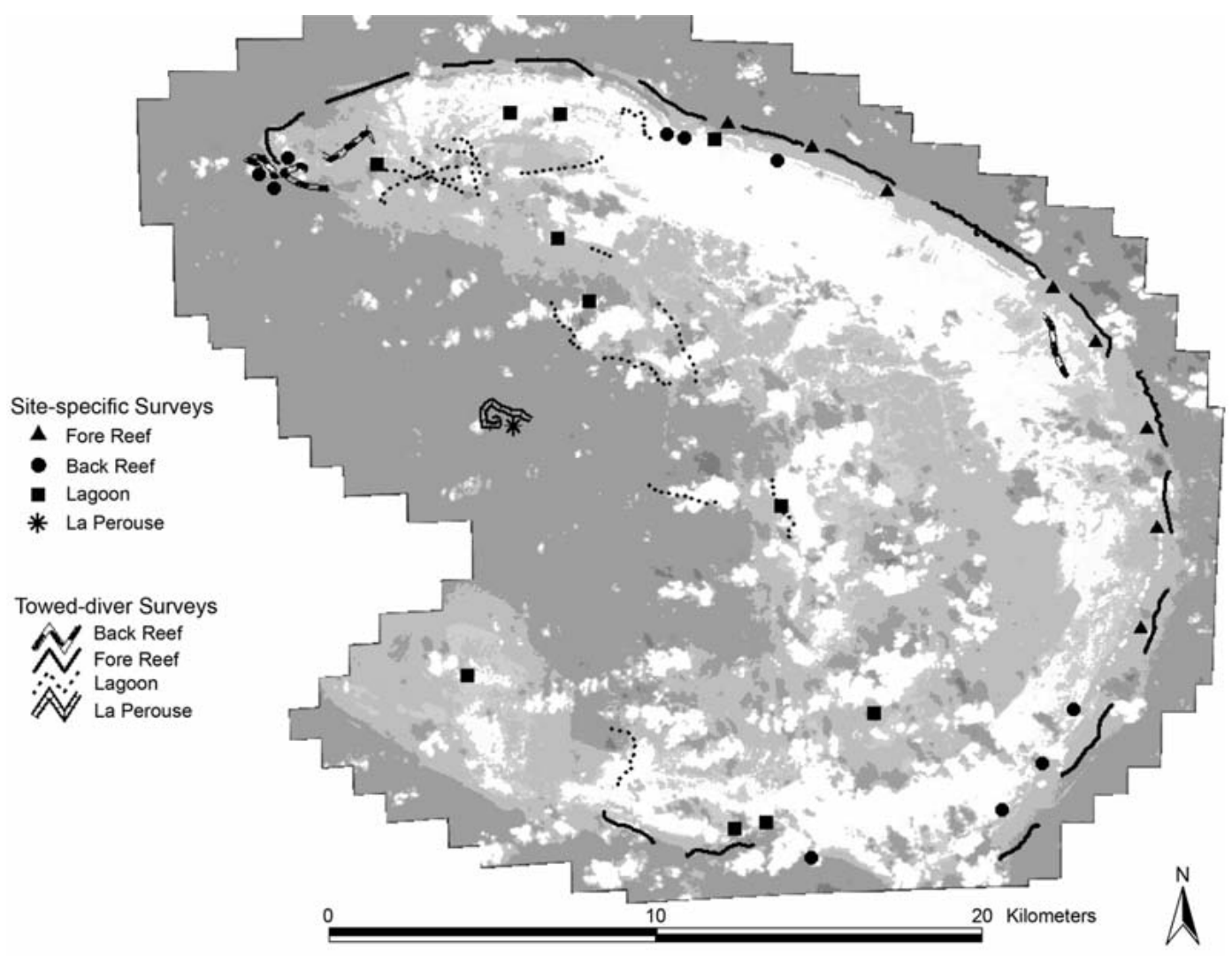

FIgURe 2. Location of towed-diver and site-specific surveys at French Frigate Shoals, NWHI, using IKONOS satellite imagery as a base map. Irregular shapes overlying much of the central lagoon are clouds.

came a focal point of renewed research activities in the NWHI. Not since the early 1980s have key components of shallow-water $(<30$ $\mathrm{m})$ benthic communities been surveyed and assessed, apart from specific interests targeting commercially important or legally protected species (e.g., Parrish and Polovina 1994). In the intervening two decades, the development of new techniques and technologies, including towed-diver surveys, computer-assisted digital image analysis, GPS (global positioning system), and GIS (geographic information system), has enabled broader survey coverage, more precise estimates of parameters relevant to benthic communities, and better spatial positioning of areas surveyed. Moreover, the accelerated pace and scale of global change during that interval, with deleterious consequences to coral reef ecosystems, have raised concerns for reef scientists, managers, and others that were of little consideration two decades ago.

Conventional coral survey methods have typically measured species diversity, percentage cover, colony abundance, and density (e.g., Loya 1972, Maragos 1972). Such parameters are useful in judging the condition of reef communities when provided in a time series for a particular location. Because they vary naturally with habitat, however, these parameters alone are not sufficient to fully assess the relative health or degradation of a reef when comparing different sites without time series (Birkeland 1999). Analyses of coral colony size-frequency distributions, which can reveal important characteristics of reef populations, can be a useful tool to estimate the response of coral populations to the 
reef environment (Bak and Meesters 1998) and in identifying trends that are already in place or are likely to occur in the absence of extreme disturbance events (Birkeland 1999). The forensic and predictive insights from data on size-class distributions thus merit their inclusion along with traditional survey measurements in long-term monitoring programs.

In this paper we describe the community structure of the shallow-water $(<20 \mathrm{~m})$ scleractinian corals at FFS, based on atoll-wide surveys conducted in 2000-2002. We assessed percentage cover using towed-diver surveys accompanied by digital video documentation over extensive areas, as well as on finer spatial and taxonomic scales using video transects and photoquadrats at numerous sites. Coral density and size-class distributions were assessed concurrently using belt transects at the same sites where video transects and photoquadrats were conducted. Percentage cover, density, and sizedistribution data were determined for coral communities that have developed in the absence of recent extreme disturbance events such as hurricanes, predator outbreaks, bleaching-induced mortality, invasive species, or anthropogenic degradation. We used these data for assessing the reefs' potential responses to salient modern stressors, following the distinction made by West and Salm (2003) between resistance and resilience and extending their definitions (which were formulated with specific reference to mass coral bleaching) to include additional stressors that have been implicated in contemporary declines of coral reefs.

\section{MATERIALS AND METHODS}

\section{Benthic Surveys}

Towed-diver surveys were conducted in 2000 (11-15 September), 2001 (13 September), and 2002 (12-13 September and 4 October) according to the methods of Kenyon et al. $(2004 a)$. Laser-projected dots used to calibrate image size did not appear on videographic imagery recorded during 2002 surveys due to mechanical problems. Habitat digital videotapes were sampled at 30-sec intervals and quantitatively analyzed for coral percentage cover using the methods of Kenyon et al. (2004a), in which the coral categories that could be distinguished were Pocillopora, massive and encrusting Porites (e.g., $P$. lobata, P. evermanni), Porites compressa, Montipora, Acropora, and other corals (e.g., Pavona, Fungia, Leptastrea). Average depth was calculated for each towed-diver survey from a temperature/pressure recorder (SBE 39, SeaBird Electronics) mounted on the habitat tow board, and survey distances were calculated using GPS and ArcView GIS 3.2.

Site-specific belt-transect surveys, along with digital video recording of benthic cover along the transect lines, were independently conducted by three separate teams of divers on 11-13 September and 4 October 2002 according to the methods described by Maragos et al. (2004) for 2002 rapid ecological assessments. Locations of belt-transect/video surveys were determined on the basis of: (1) filling gaps in the locations of baseline assessments conducted during two expeditions to the NWHI in 2000 and 2001, (2) depths that allowed three dives per day per diver, (3) constraints imposed by other ship-supported operations, and (4) sea conditions. Surveys began by videotaping along two 25 -m transect lines, whose ends were separated by about $5 \mathrm{~m}$, and which were set along a single depth at each site, laid out by a team of fish observers before the benthic observers' water entry. The videographer swam approximately $1 \mathrm{~m}$ above the transect line with the camera lens pointing directly downward and also recorded $360^{\circ}$ views of the surrounding area at the beginning and end of each transect line. Then, on the swim back along the transect lines, each coral colony whose center fell within a 1-m-wide strip on each side of the line $(0.5 \mathrm{~m}$ at densely populated sites) was categorized as having a maximum diameter belonging to one of seven size classes (Mundy 1996): $0-5 \mathrm{~cm}, 5-10 \mathrm{~cm}, 10-20 \mathrm{~cm}$, 20-40 cm, 40-80 cm, 80-160 cm, or $>160$ $\mathrm{cm}$. Colonies were recorded at the genus level for Pocillopora, Montipora, Acropora, Porites, Fungia, Pavona, and Psammocora and at the family level for Faviidae (genera Leptastrea 
and Cyphastrea). For species in which clonal propagation (e.g., Porites compressa) or fissioning (e.g., Porites lobata) is an important part of the life history strategy, consideration was given to tissue color, interfaces with neighboring conspecifics, and distance between conspecifics in determining the number of colonies. Either $25 \mathrm{~m}^{2}, 50 \mathrm{~m}^{2}$, or $100 \mathrm{~m}^{2}$ was surveyed at each site, depending on the density of colonies and available dive time.

Twelve $(35$ by $50 \mathrm{~cm}$ ) photoquadrats were concurrently photographed with spatial reference to the same two $25-\mathrm{m}$ transect lines (i.e., six photoquadrats per transect) at each site according to the methods of Preskitt et al. (2004). Corals were identified to species or genus from color-adjusted digital photos imported into the PhotoGrid software program, and percentage cover was determined using 100 randomly placed points on each digital image. Site-specific coral species lists, compiled during belt-transect surveys coupled with a random swim in the vicinity of the transect lines at the end of each survey, assisted with the identification of species from digital imagery. Corals that could not be resolved to the genus level were pooled as "other live coral."

\section{Data Extraction and Analysis}

For each site, the software program DVRaptor-RT Video (Canopus Corporation) was used to capture adjacent, nonoverlapping still frames along the length of each transect line. Due to varying distance of the videographer above the transect line among sites, the number of captured still frames per transect varied among sites (range: 19-30 frames per transect), as did the total area thereby recorded (range: $23.1-57.7 \mathrm{~m}^{2}$ per transect). To establish the sample size (number of analyzed frames) for each transect to equalize the area analyzed, a preliminary analysis was conducted for each of four transects that yielded 25 captured still frames (i.e., each frame averaged 1 by $1.33 \mathrm{~m}$, given the $3: 4$ aspect ratio of the captured images). For each of the four transects, all 25 captured still frames were analyzed in random order for percentage coral cover according to the method described in
Kenyon et al. (2004a). The taxa that could be identified were Pocillopora meandrina, $P$. eydouxi, $P$. damicornis, $P$. ligulata, massive and encrusting Porites (e.g., P. lobata, P. evermanni), Porites compressa, Montipora, Faviidae, Pavona, Fungia, Acropora cytherea, A. bumilis, and $A$. valida. For all four transects, cumulative values for total coral percentage cover leveled off at 12 frames. The benthic area included within 12 frames $\left(16 \mathrm{~m}^{2}\right)$ was then used to compute the number of frames that were randomly selected from other transects to yield an equivalent benthic area for analysis.

Transect site locations and tracks of towed-diver surveys georeferenced with nondifferentially-corrected GPS units (Garmin model 12) were mapped using ArcView GIS 3.2. For analytical purposes, toweddiver and site-specific surveys were spatially grouped according to habitat (forereef, backreef, lagoon, La Perouse Pinnacles) and geographic sector (N, NE, E, etc.).

Differences in total percentage coral cover among habitats, and among sectors within habitats, were examined using one-way analysis of variance (ANOVA). Kruskal-Wallis tests were used with percentage cover data from surveys in which the data were not normally distributed, even with transformations, or had unequal variances. Differences in the percentage cover of coral genera among habitats, and among sectors within habitats, were examined using the chi-square test of independence between two or more samples, aggregating all taxa other than Porites, Pocillopora, and Acropora. Statistical analyses were conducted using SigmaStat software (SPSS Inc.).

Maragos et al. (2004) provided two indices of the relative occurrence and abundance of 41 coral species at FFS based on qualitative rapid ecological assessment surveys at 85 sites. To compare these indices with the relative abundance of coral species determined through percentage cover analysis of photoquadrats in this study, we first ranked the 41 values in each of the Maragos et al. (2004) indices from highest (rank $=1)$ to lowest. We next added the two ranked scores together to produce a single, summed score for each 
species (e.g., occurrence rank $1+$ abundance rank $3=$ summed score 4 ). Last, these summed scores were ranked to determine species' relative abundance for Maragos et al. (2004) survey data.

\section{RESULTS}

\section{Towed-Diver Surveys}

The distance between sample frames captured at 30-sec intervals depends upon the tow speed; the average interframe distance ranged from 14.7 to $35.5 \mathrm{~m}$ (mean $=24.4 \mathrm{~m}$, $n=38$ tows). The average benthic area captured in laser-scaled frames was $9,692 \mathrm{~cm}^{2}$ ( $\mathrm{SE}=115 \mathrm{~cm}^{2}, n=2,000$ frames). Towed divers surveyed $88.9 \mathrm{~km}$ of benthic habitat (Table 1, Figure 2), from which 3,625 captured frames were analyzed. This benthic analysis area $\left(3,513 \mathrm{~m}^{2}\right)$ sampled a total survey area of $101,060 \mathrm{~m}^{2}$, given the $3: 4$ aspect ratio of the captured frames (Table 1). Survey effort emphasized the forereef habitat, because towed divers were able to work in conditions of high swell or strong current that were too extreme for roving divers to survey safely. The backreef habitat received little survey coverage with towed divers, because the tow boat could not safely maneuver in the shallow depths. Total average coral cover over this area was low to moderate, ranging from $7.7 \%$ in the lagoon to $20.8 \%$ around $\mathrm{La} \mathrm{Pe}$ rouse Pinnacles (Table 1, Figure $3 a$ ). The differences among the four habitats in their average total percentage coral cover were not significant (Kruskal-Wallis test, $H=3.19$, $\mathrm{df}=3, P=0.36)$. However, a significant difference existed among habitats in the relative abundance of coral genera present (chisquare test, $\mathrm{X}^{2}=81.33, \mathrm{df}=9, P=0.00$ ). With the exception of eastern-facing reefs, the coral genus Porites, particularly species with massive and encrusting growth forms (e.g., P. lobata, P. evermanni), dominated the coral fauna in all habitats and sectors (Table 1, Figure $3 a$ ). Pocilloporids dominated or codominated eastern- and northeastern-facing assemblages within the forereef and backreef habitats. Acroporids had a patchy distribution, primarily in northerly and southern en- vironments and around La Perouse Pinnacles. Montiporids and genera in other coral families were rare throughout all habitats and sectors.

The average coral cover across $50,814 \mathrm{~m}^{2}$ surveyed along the forereef was $8.8 \%$ (Table 1). Although the differences among the average total percentage coral cover in the six forereef sectors were not significant (oneway ANOVA, $F=2.18 ; \mathrm{df}=5,13 ; P=$ 0.12 ), there were significant differences in the relative abundance of coral genera present (chi-square test, $\mathrm{X}^{2}=286.60, \mathrm{df}=15$, $P=0.00)$. Porites dominated all forereef sectors except as noted in the preceding paragraph, typically accounting for more than two-thirds of the coral cover. Pocilloporids were generally the next most dominant member of the coral fauna on the forereef, with the exception of the northwestern (NW) and southern (S) exposures, where acroporids achieved higher cover than pocilloporids. Porites compressa was poorly represented on the forereef along with other coral genera that were rare throughout the atoll (Table 1, Figure $3 a$ ).

The average coral cover across $9,890 \mathrm{~m}^{2}$ surveyed along the backreef was $18.9 \%$ (Table 1). The backreef habitat was not as evenly sampled across different atoll sectors as was the forereef habitat (Figure 2) due to difficulties in safely maneuvering the tow boat in this shallow environment. Analysis of backreef surveys along the NW exposure showed a total coral cover value $(25.0 \%)$ equivalent to that of forereef environments in the same sector (Table 1). The composition of the coral fauna in the NW backreef habitat, however, was significantly different from that on the NW forereef (chi-square test, $\mathrm{X}^{2}=$ 11.22, $\mathrm{df}=3, P=0.01$ ), with acroporids more abundant on the NW backreef than on the NW forereef. A single survey along the eastern (E) backreef (Figure 2) revealed scoured pavement largely devoid of live coral ( $<1 \%$ cover), which mainly consisted of pocilloporids (Table 1).

The average coral cover across $37,287 \mathrm{~m}^{2}$ surveyed in the lagoon habitat was $7.7 \%$ (Table 1). Although the differences among the average total percentage coral cover in the 


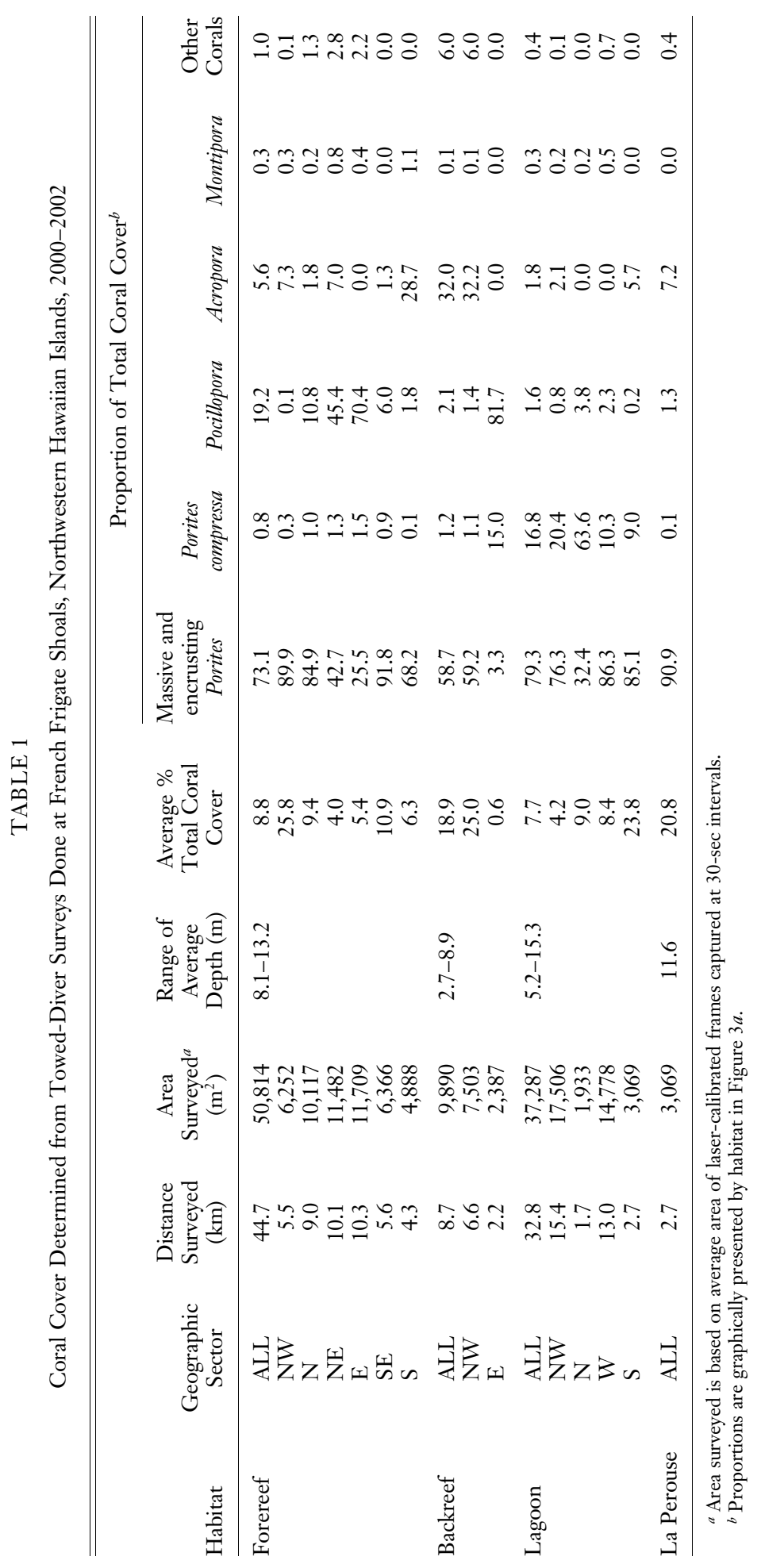



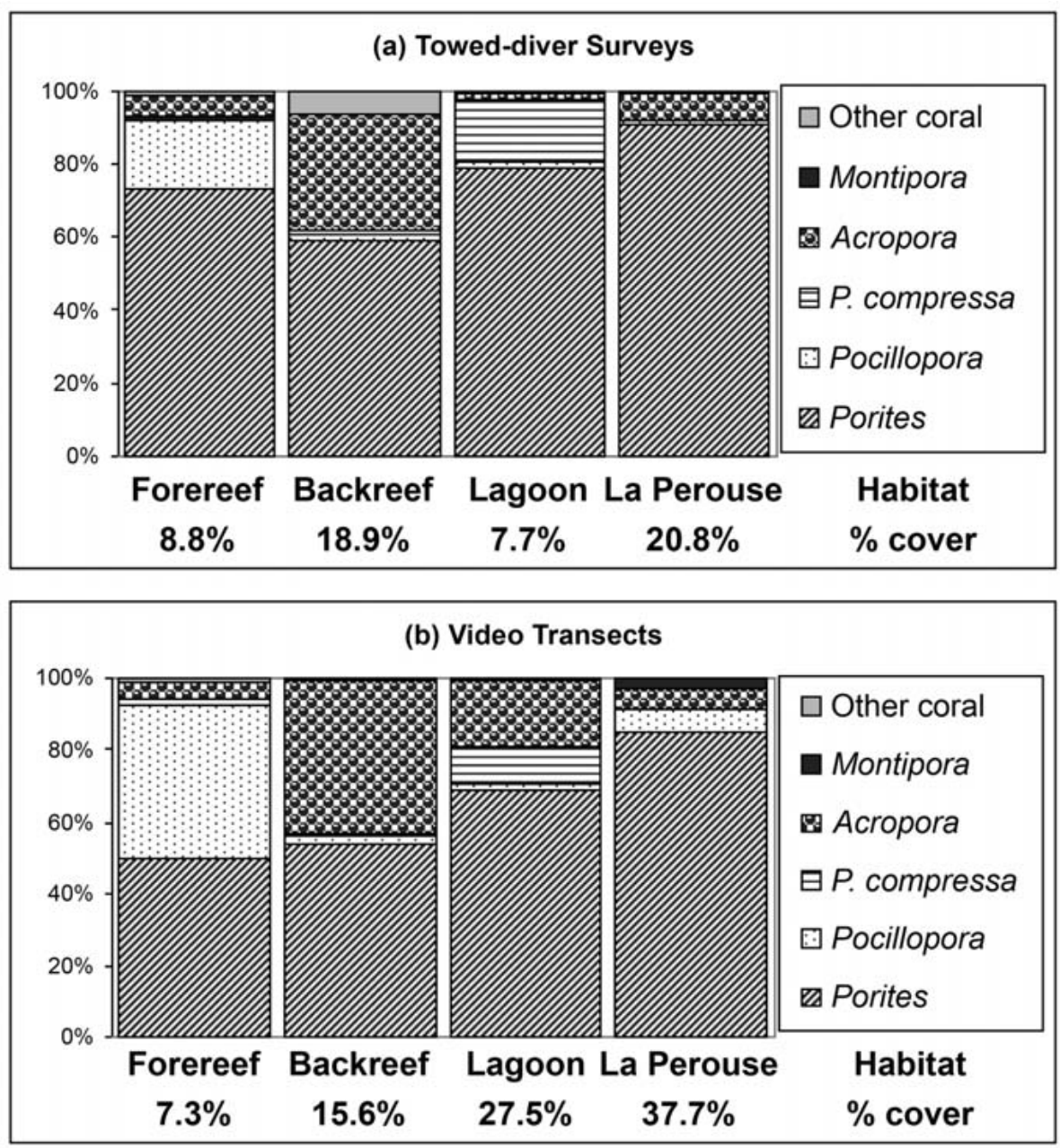

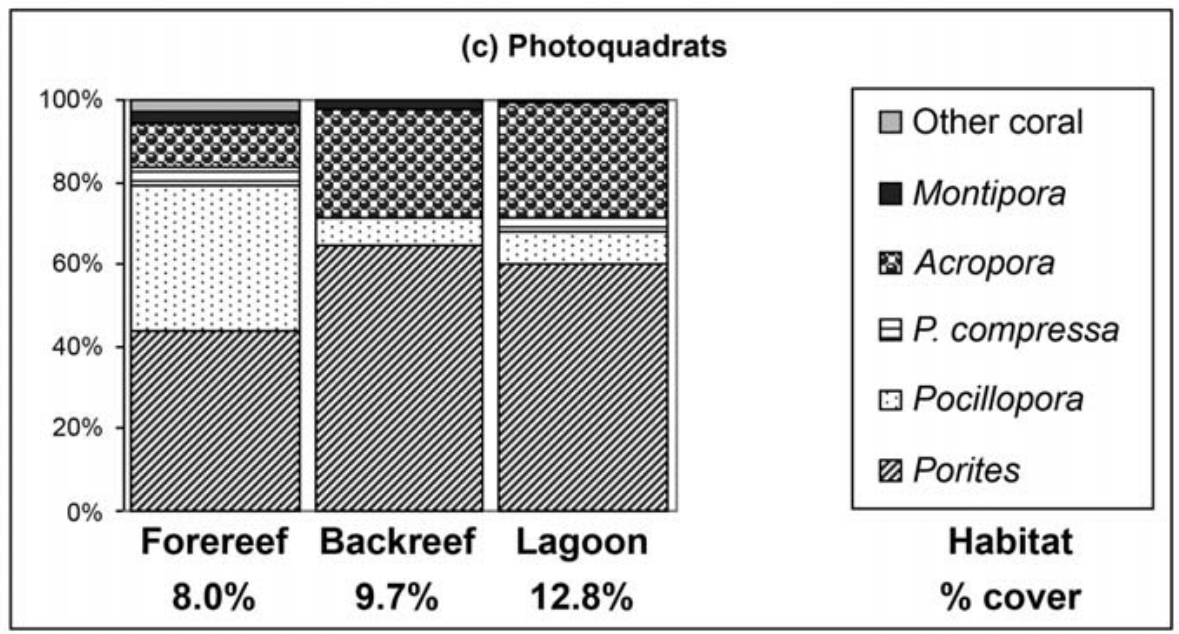


four lagoon sectors were not significant (Kruskal-Wallis test, $H=5.90, \mathrm{df}=3, P=$ 0.12 ), there were significant differences in the relative abundance of coral taxa (chisquare test, $\left.\mathrm{X}^{2}=123.30, \mathrm{df}=9, P=0.00\right)$. Porites compressa, which was more abundant in the lagoon than in any other habitat (Figure $3 a$ ), was particularly well represented on patch reefs in the northern part of the lagoon (Table 1). Acroporids were encountered only on northwestern and southern lagoon surveys, among the same sectors where they were most abundant on the forereef.

The highest coral cover of any habitat at French Frigate Shoals occurred on the shallow $(<15 \mathrm{~m})$ substrate surrounding $\mathrm{La}$ Perouse Pinnacles (Table 1). As in other habitats, massive and encrusting Porites accounted for the preponderance of the coral cover (Figure 3a). Acropora populations were also well represented in this habitat (Table 1).

\section{Site-Specific Surveys: Video Transects}

A total of $896 \mathrm{~m}^{2}$ at 28 sites $\left(32 \mathrm{~m}^{2} /\right.$ site $)$ was quantitatively assessed from transect videotapes. Overall coral cover was lowest on the forereef $(7.3 \%)$, with progressively greater cover on the backreef (15.6\%), lagoon (27.5\%), and around La Perouse Pinnacles $(37.7 \%$ ) (Table 2, Figure 3b). The differences among the four habitats in their average total percentage coral cover were not significant (Kruskal-Wallis test, $H=6.58, \mathrm{df}=3, P=$ 0.087).

Eleven of the 13 taxa that could be distinguished in NWHI video transects (see Materials and Methods) were seen in FFS video transects; only Pocillopora ligulata and Fungia were not seen. A significant difference existed among the four habitats in the relative abundance of coral genera present (chi-square test, $\mathrm{X}^{2}=157.55$, df $=9, P=0.00$ ). The genus Porites, particularly species with massive and encrusting growth forms, dominated or codominated all habitats (Table 2, Figure 3b). The forereef habitat, surveyed with video transect methods only along northeastern and eastern exposures (Figure 2), was codominated by pocilloporids (Table 2, Figure $3 b$ ). Of the three distinguishable species of Pocillopora present in video transects, $P$. meandrina composed $93.7 \%$ of the total pocilloporid cover throughout the atoll. The backreef habitat, which was not sampled with video transect methods along the eastern exposure (Figure 2), was codominated by acroporids (Table 2, Figure 3b). Of the three distinguishable species of Acropora present, $A$. cytherea composed $89.1 \%$ of the total acroporid cover throughout the atoll. Porites compressa was more abundant in the lagoon than in any other habitat (Table 2, Figure 3b). Montiporids and other coral taxa were rare throughout all habitats (Table 2, Figure 3b).

\section{Site-Specific Surveys: Photoquadrats}

Video transects and photoquadrats were concurrently recorded at 26 sites. Total coral percentage cover calculated by the two methods differed by more than $10 \%$ at six sites. Photoquadrat data from these six sites were excluded from further analysis because the smaller benthic area quantitatively assessed by photoquadrat methods $\left(2.1 \mathrm{~m}^{2} /\right.$ site $)$ was considered to generate a less-representative indicator of coral cover than that generated by the larger area $\left(32 \mathrm{~m}^{2} / \mathrm{site}\right)$ quantitatively assessed by video transects. Of the remaining 20 sites, the average of the absolute values of the difference between video transect and photoquadrat total coral percentage cover was $2.3 \%$. Overall coral cover was lowest on the forereef $(8.0 \%)$, with progressively greater cover on the backreef $(9.7 \%)$ and the lagoon (12.8\%) (Table 2, Figure 3c). The single site surveyed at La Perouse Pinnacles was among the six sites dropped from further photoquadrat analysis. The differences among the three habitats in their average total percentage coral cover were not significant

FIGURE 3. $a-c$, Relative abundance of primary coral taxa by habitat at French Frigate Shoals, NWHI, derived by three different methods. Values below habitat labels are total coral percentage cover within each habitat. Porites $=$ massive and encrusting Porites. 


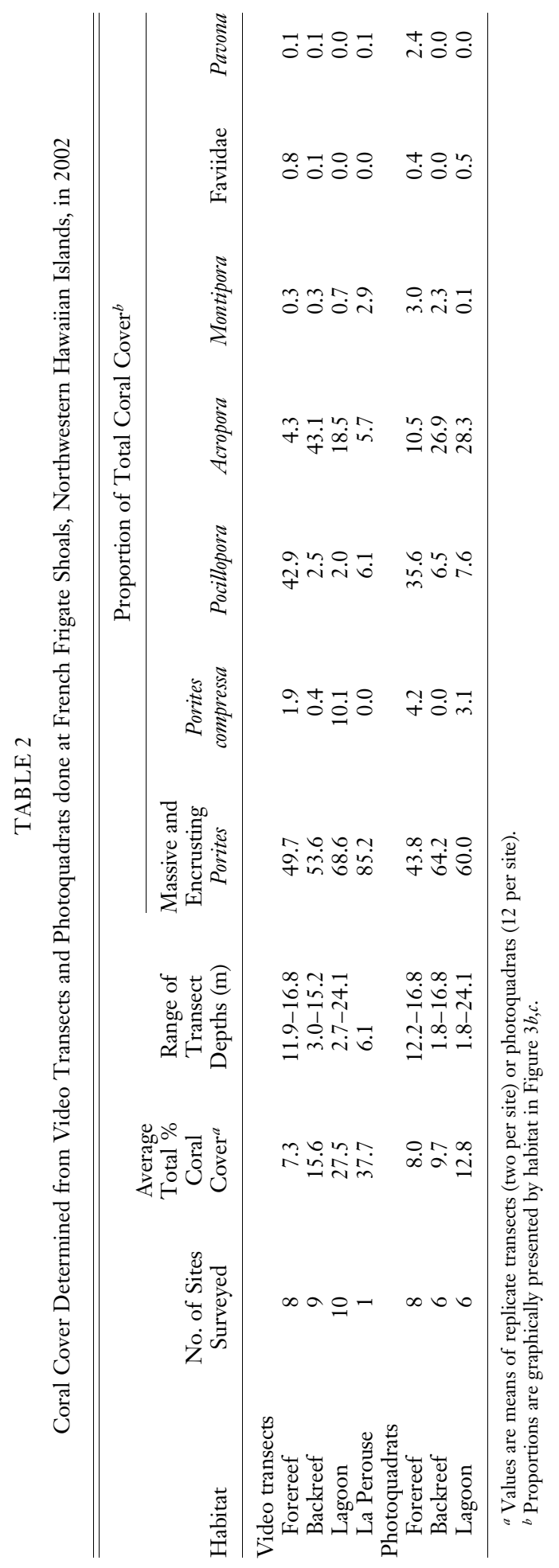


TABLE 3

Relative Abundance of Coral Species at French Frigate Shoals Ranked by Photoquadrats in This Study, in Maragos et al. (2004), and in Grigg (1983)

\begin{tabular}{clll}
\hline \hline Rank & This Study & Maragos et al. (2004) & Grigg (1983) \\
\hline 1 & Porites lobata & Porites lobata & Porites lobata \\
2 & Acropora cytherea & Pocillopora meandrina & Acropora cytherea \\
3 & Pocillopora meandrina & Porites compressa & Pocillopora meandrina \\
4 & Pocillopora eydouxi & Montipora capitata & Pavona duerdeni \\
5 & Porites evermanni & Acropora cytherea & Acropora valida \\
6 & Porites compressa & Cyphastrea ocellina & Porites compressa \\
7 & Pocillopora ligulata & Porites evermanni & Montipora verrucosa \\
8 & Pavona duerdeni & Pavona duerdeni & Montipora dilitata \\
9 & Montipora capitata & Pocillopora ligulata & Pocillopora damicornis \\
10 & Cyphastrea ocellina & Pocillopora damicornis & Cyphastrea ocellina \\
11 & Leptastrea purpurea & Montipora patula & Montipora flabellata \\
12 & Pocillopora damicornis & Pocillopora eydouxi & Porites brighami \\
13 & Acropora bumilis & Porites brighami & N.A. ${ }^{\text {b }}$ \\
\hline
\end{tabular}

${ }^{a}$ Revised as Montipora capitata (Maragos 1995).

${ }^{b}$ Not available; data provided for only 12 species by Grigg (1983).

(one-way ANOVA, $F=0.15 ; \mathrm{df}=2,17 ; P=$ $0.86)$.

Thirteen scleractinian coral taxa were seen in FFS photoquadrats (Table 3). A significant difference existed among the three habitats in the relative abundance of coral genera present (chi-square test, $\mathrm{X}^{2}=47.65$, df $=6, P=$ 0.00). The coral genus Porites, particularly species with massive and encrusting growth forms, dominated or codominated all habitats (Table 2, Figure 3c). The forereef habitat, surveyed with photoquadrat methods only along northeastern and eastern exposures (Figure 2), was codominated by pocilloporids (Table 2, Figure 3c), similar to results obtained from video transects (Table 2) and towed-diver surveys (Table 1). Of the four species of Pocillopora present in photoquadrats, $P$. meandrina composed $61.2 \%$ of the total pocilloporid cover, and $P$. eydouxi composed $15.8 \%$ of the cover throughout the atoll using this method. The backreef habitat, which was not sampled with photoquadrat methods along the eastern exposure (Figure 2) was codominated by acroporids, similar to results from video transects (Table 2) and towed-diver surveys on the NW backreef (Table 1). The lagoon habitat was also codominated by acroporids (Table 2, Figure $3 c$ ). Acropora cytherea composed $96.8 \%$ of the total acroporid cover throughout the atoll. Montiporids and other coral taxa were rare throughout all habitats (Table 2, Figure 3c).

\section{Site-Specific Belt-Transect Surveys: Colony Density and Size Classes}

A total of 5,954 colonies was counted and classified by size class within belt transects covering $1,800 \mathrm{~m}^{2}$ at 29 sites. Size-class data were not collected during the single survey at La Perouse Pinnacles. Porites was the most numerically abundant (i.e., highest density) taxon across the atoll system, followed by $\mathrm{P}_{0}$ cillopora, Acropora, Faviidae, Montipora, and Pavona (Figure 4, All Habitats). All but 16 colonies (99.7\%) of Fungia and Psammocora were in those taxa.

Relative densities of coral taxa followed a pattern within each surveyed habitat (forereef, backreef, lagoon) similar to that across the atoll system (Figure 4) (i.e., in each habitat, Porites, followed by Pocillopora, was the most numerically abundant taxon). With the exception of the lagoon habitat, Acropora was the next most abundant taxon. The relative abundance rank of faviids, Montipora, and Pavona varied among habitats, but all three taxa had a consistently low $(\leq 0.22$ colonies per square meter) density. Highest overall 


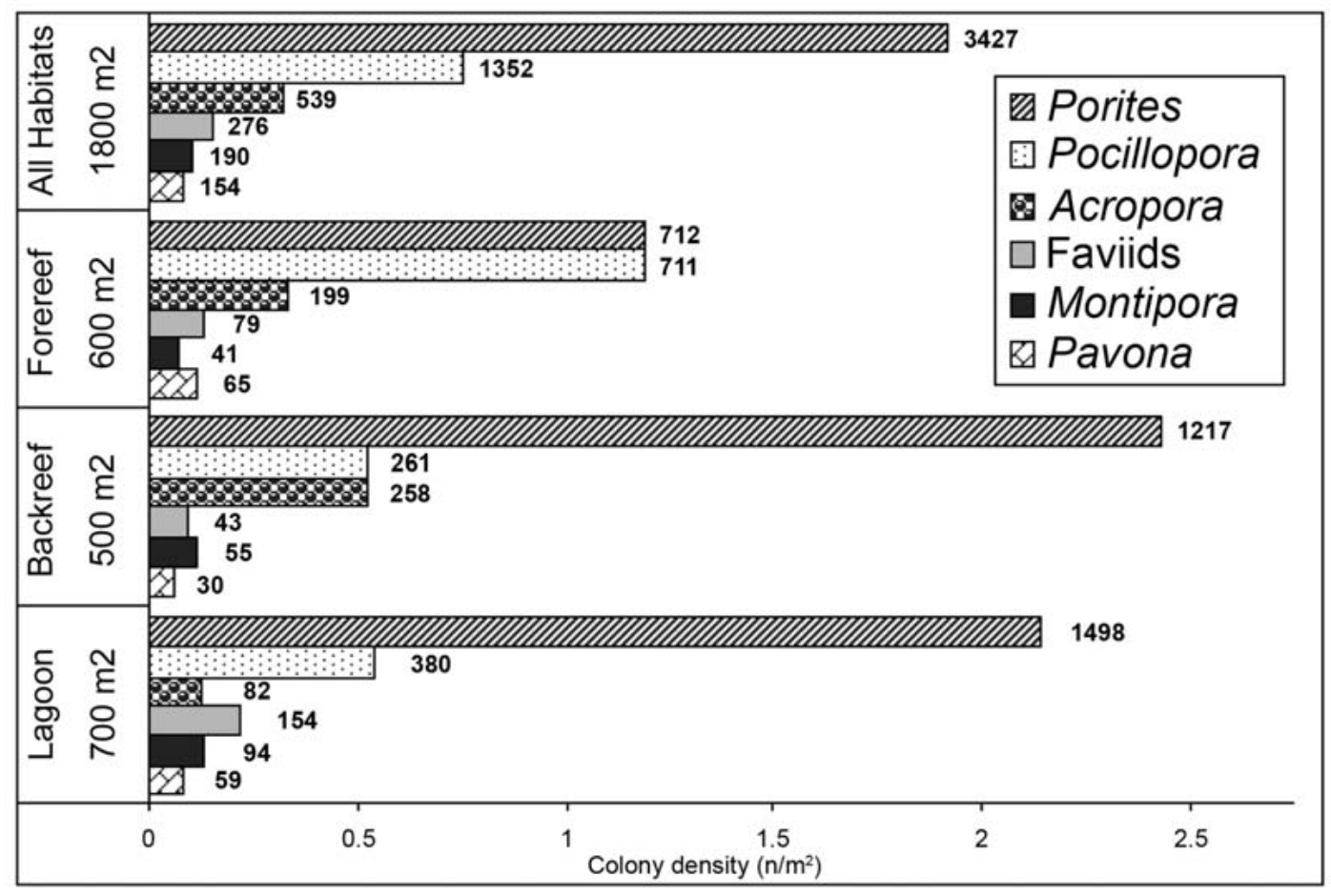

FIGURE 4. Colony density $\left(n / \mathrm{m}^{2}\right)$ of six coral taxa at French Frigate Shoals, NWHI, in the lagoon, backreef, forereef, and the three habitats combined. Number of colonies $(n)$ was determined from belt-transect surveys; area $\left(\mathrm{m}^{2}\right)$ surveyed in each habitat is shown next to habitat label. Values to the right of bars are the number of colonies of each taxon.

colony density occurred on the backreef $(0.62$ colonies per square meter) and lowest on the forereef $(0.50$ colonies per square meter).

The distribution of Porites size classes was skewed toward smaller colonies $(<20 \mathrm{~cm})$ in all habitats (Figure $5 a-c$ ). Few Porites colonies (7.6\% of total) exceeded $20 \mathrm{~cm}$ in diameter on the forereef (Figure 5a), where their density was lowest (Figure 4). One-fourth (25\% of total) of Porites colonies exceeded $20 \mathrm{~cm}$ in diameter in both backreef and lagoon habitats (Figure $5 b, c$ ), where their densities were the highest calculated for all taxa and habitats in this study (Figure 4).

The densities of pocilloporids on the backreef and in the lagoon were very similar and less than half their density on the forereef (Figure 4). Moreover, their size-class distributions on the backreef and in the lagoon were also similar (Figure $5 e, f$ ) and differed from those on the forereef (Figure $5 d$ ) only in the relative proportion of colonies in small $(5-10 \mathrm{~cm})$ and intermediate $(10-20 \mathrm{~cm})$ size classes.

Histograms of Acropora size classes (Figure $6 a-c)$ show transitions from a distribution skewed toward smaller size classes on the forereef, to a more bell-shaped distribution on the backreef, to a more uniform distribution (with the exception of a paucity of the smallest size class, $<5 \mathrm{~cm}$ ) in the lagoon. More than half (54.3\%) of the Acropora colonies in the lagoon exceeded $40 \mathrm{~cm}$ in diameter, with only half as many $(27.1 \%)$ attaining such sizes on the backreef; no Acropora colonies exceeded $40 \mathrm{~cm}$ on the forereef. Acropora density was lowest in the lagoon and highest on the backreef, with intermediate values on the forereef (Figure 4).

Faviids, which never exceeded $40 \mathrm{~cm}$ in diameter (Figure $6 d-f$ ), had low densities $(\leq 0.22$ colonies per square meter) in all hab- 



FIgure 5. Size-class distributions, by habitat, of scleractinian corals at French Frigate Shoals, NWHI. $a-c$, Porites; $d-f$, Pocillopora. 

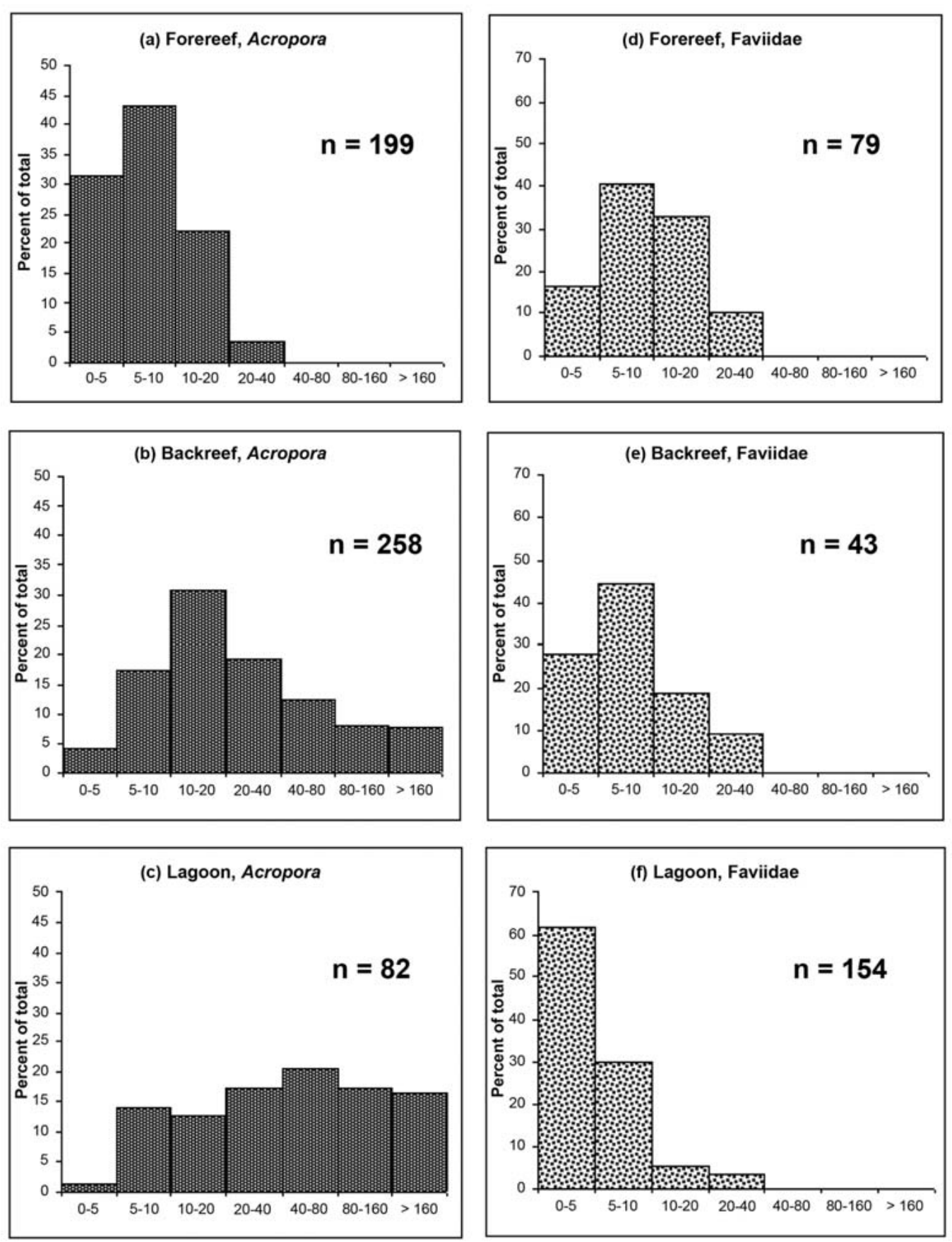

Figure 6. Size-class distributions, by habitat, of scleractinian corals at French Frigate Shoals, NWHI. $a-c$, Acropora; $d-f$, Faviidae. 
itats (Figure 4). Less than half (38.3\%) of faviid colonies in the lagoon exceeded $5 \mathrm{~cm}$ in diameter, and more than $75 \%$ of faviid colonies exceeded that size on the forereef and backreef. The density of Montipora colonies was low $(\leq 0.13$ colonies per square meter) in all habitats (Figure 4). Although few $(<8 \%)$ Montipora colonies exceeded $40 \mathrm{~cm}$ in diameter in any habitat (Figure $7 a-c$ ), each habitat had a distinctive size-class distribution, with the largest colonies occurring in the lagoon (Figure 7c). Pavona (Figure 7d-f), which exceeded $40 \mathrm{~cm}$ in diameter only in the lagoon, had low densities $(\leq 0.11$ colonies per square meter) in all habitats (Figure 4). The majority of Pavona colonies $(93.5 \%, n=154)$ measured between 5 and $20 \mathrm{~cm}$ in diameter.

\section{DISCUSSION}

\section{Comparison with Previous Surveys}

The three survey methods used in this study yielded highly congruent patterns in the atoll-wide distribution and abundance of coral genera. Dominance in all habitats by Porites (Tables 1, 2), especially those species with massive and encrusting growth forms, is consistent with the top ranking of Porites lobata by Maragos et al. (2004) (Table 3) and expands upon a generalization by Grigg (1983) that Porites lobata is generally the most abundant species at all southwest-sector stations surveyed throughout the Hawaiian Archipelago. The abundance of acroporids in the northwestern and southern sectors of the atoll and around La Perouse Pinnacles (Tables 1,2 ) is consistent with observations of Grigg et al. (1981) that the most welldeveloped Acropora colonies occurred on the southwestern end of the atoll near Disappearing Island (which was completely eroded below sea level during our surveys).

Earlier quantitative surveys of corals at FFS (Grigg 1983) were limited to seven 50-m transects along the seaward, southwest sector within a narrow depth range $(7-13 \mathrm{~m})$, from which a mean coral cover of $69 \%$ was calculated. However, Grigg's surveys throughout the Hawaiian Archipelago deliberately emphasized southwestern exposures at depths close to $10 \mathrm{~m}$, where earlier studies had documented the best-developed seaward reefs. Total coral cover close to this value was calculated at only two sites in our study using video-transect data $(59.9 \%$ at a southern lagoon site and $65.7 \%$ at a northeastern backreef site); such high coral cover values were anomalous across broader, atollwide surveys. The majority $(64.3 \%)$ of sites had $<20 \%$ coral cover.

Of 57 species of scleractinian corals documented in the NWHI, 41 have been recorded at FFS (Maragos et al. 2004). Thirteen species were distinguished using photoquadrats in this study (Table 3). Of these 13 species, 11 are included among the top 13 species ranked with the use of occurrence and abundance indices developed by Maragos et al. (2004) from surveys at 85 sites throughout the atoll (Table 3). Three species ranked among the most highly abundant by Grigg (1983), Acropora valida, Montipora dilitata, and M. flabellata, were absent from the top 13 species ranked with data from Maragos et al. (2004) or photoquadrats (Table 3). Grigg's quantitative surveys were conducted exclusively along southwestern seaward reefs, however, and therefore reflect more localized abundances than do atoll-wide surveys.

\section{Population Variations among Habitats}

Percentage cover data from all three methods revealed significant differences among the atoll habitats in the relative abundance of coral genera. Moreover, colony densities and size-class distributions of salient genera in each habitat reveal genera-specific responses to the physical and biotic regimes within that habitat. With the exception of Pavona on the backreef, the continuity of all sizeclass distributions, without gaps in the representation of any size categories, suggests successful recruitment of new colonies (via sexual or asexual processes) as well as the absence of widespread catastrophic mortality due to storms, disease, predator infestations, or other extreme disturbance events (Birkeland 1999). The absence of extreme disturbance in the recent past can also be inferred from a community structure that is character- 

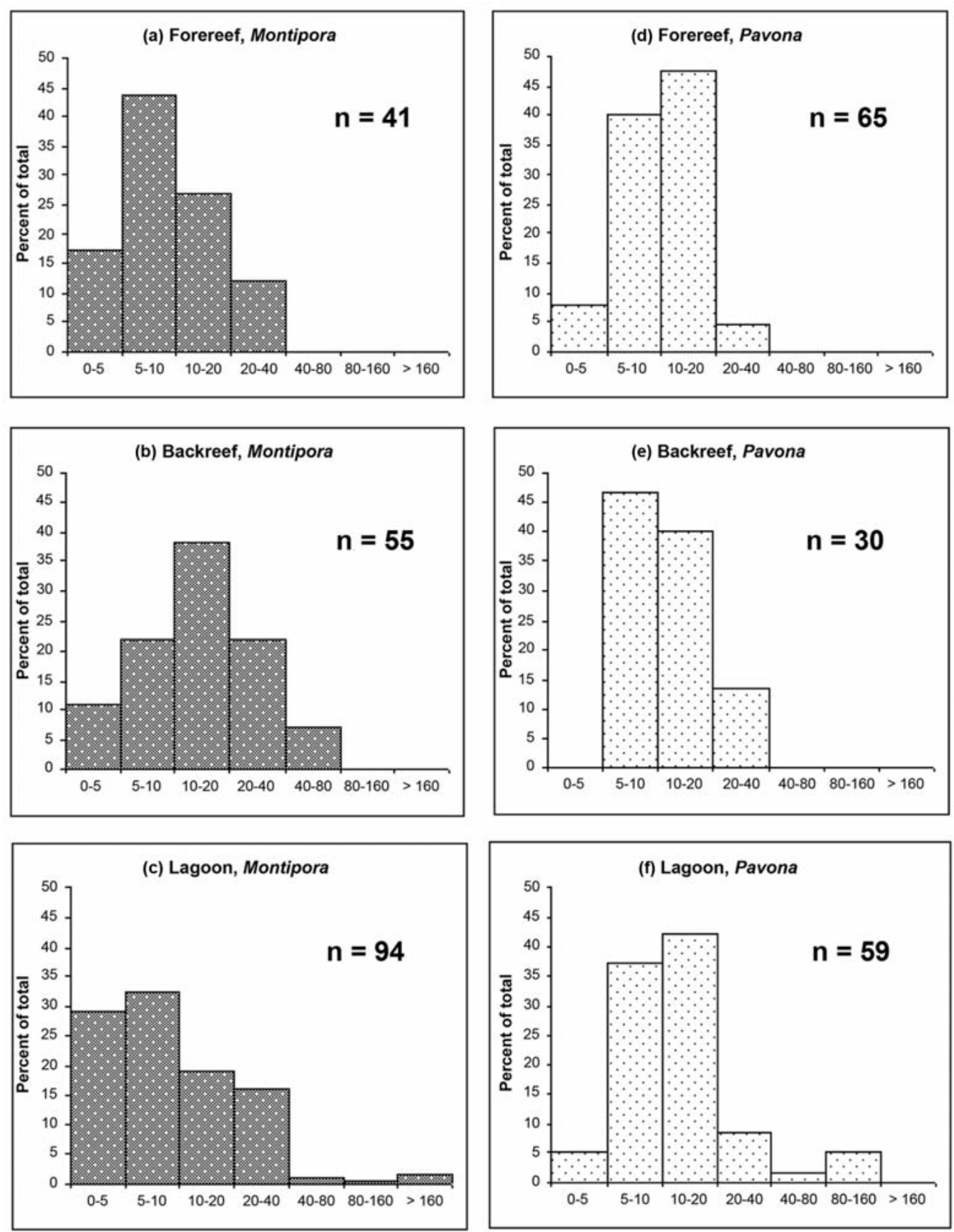

FIgUre 7. Size-class distributions, by habitat, of scleractinian corals at French Frigate Shoals, NWHI. $a-c$, Montipora; $d-f$, Pavona. 
ized by high dominance by few taxa (Dollar 1982, Grigg 1983).

Consistent with the dominance of Porites and Pocillopora on the forereef (Figure 3) is their identical colony density (Figure 4) that was measured along the northeastern/eastern sector. Porites species with massive and encrusting growth forms, although capable of constructing colonies measuring meters in diameter (Dollar 1982, Chess et al. 1997; J.C.K., unpubl. data), rarely exceed $20 \mathrm{~cm}$ in diameter on these forereef sectors (Figure $5 a$ ), most likely due to high-energy sea conditions generated by the trade-wind seas that typify these exposures (Grigg 1983; R. Brainard, pers. comm.). Hawaiian pocilloporid species rarely exceed $40 \mathrm{~cm}$ in diameter (Polachek 1978, Bailey-Brock et al. 1994, Chess et al. 1997). The similarity of the Pocillopora size-class distribution on the forereef to those from more protected backreef and lagoon habitats (Figure $5 d-f$ ) underscores the suitability of its dense skeletal structure (Houck 1978) and branched colony morphology, which acts as a baffle to high-energy water motion, to surviving in high-energy exposures (Dollar 1982). The paucity (2.5\%) of acroporids greater than $20 \mathrm{~cm}$ in diameter on the forereef (Figure $6 a$ ) also likely reflects consistent exposure to heightened wave energy and long-period swell (R. Brainard, pers. comm.).

Wave energy dissipated by the reef crest renders the shallow backreef habitat a more benign environment than the forereef in terms of the magnitude of physical energy from water movement. The higher density (Figure 4) and increased proportion of large $(>20 \mathrm{~cm}$ diameter) Porites colonies on the backreef relative to the forereef (Figure $5 a, b$ ) are consistent with reduced disturbance from wave stress (Dollar 1982). In contrast, both density and percentage cover of pocilloporids, which thrive in harsh areas of high wave energy (Maragos 1972, Dollar 1982), are low on the backreef (Tables 1, 2, Figures 3, 4). The codominance (Tables 1, 2, Figure 3), high density (Figure 4), and broad range of sizes of acroporids on the backreef (Figure 6b) are also consistent with reduced physical disturbance from wave energy on the backreef.
The vast (727 $\mathrm{km}^{2}$ [NOAA 2003]) lagoon at FFS is dotted with sandy islets whose shape and size constantly are being changed by waves and currents and with numerous patch reefs that vary considerably in size, composition, and abundance of stony corals. Consequently, coral assemblages within the lagoon are the most difficult for which to draw generalizations. The most striking difference between coral assemblages in the lagoon and those in other habitats is the greater proportion of the Hawaiian-endemic, branching species Porites compressa (Tables 1, 2) in the lagoon. This readily fragmenting species can form extensive, monospecific thickets (Polacheck 1978, Dollar 1982), in which the boundaries between genets can be difficult to discern visually (Hunter 1993). The presence of multiple small fragments largely accounts for the high number of small colonies in the right-skewed distribution of Porites in the lagoon (Figure $5 c$ ), and the clonally propagated stands contribute to the proportion of large ( $>40 \mathrm{~cm}$ diameter) colonies. The nearly identical percentage cover, density, and size-class distribution of pocilloporids in the lagoon and backreef (Tables 1, 2, Figures 4, 5e-f) suggest comparable levels of wave stress in the two habitats (Dollar 1982).

\section{Capacity for Resistance and Resilience to Selective} Stressors

Assessing resilience, the ability of reefs to recover from disturbance (McClanahan et al. 2002, Hughes et al. 2003, West and Salm 2003) through growth, reproduction, and recruitment, is increasingly important as the variety and magnitude of stressors intensify worldwide. West and Salm (2003) noted that reefs with effective management that minimizes anthropogenic stresses are likely to have higher resilience than reefs that are already suffering from multiple stressors. Protective federal legislation since 1909 coupled with remoteness from population centers has historically spared the reefs of FFS from considerable degradation connected to human activity. Human intervention, such as lagoon dredging for military use during World War II (Amerson 1971) and ship groundings (e.g., 
Dollar and Grigg 1981), nonetheless caused localized disturbances to coral communities. Though low to moderate levels of nickel, copper, lead, PCBs, and DDT have been detected in lagoon sediments (Turgeon et al., in Maragos and Gulko 2002), metallic waste and toxic chemicals left behind from military activities are being removed (Maragos and Gulko 2002). Reduced fishing pressure due to management by the National Marine Fisheries Service has resulted in fish communities that are dominated by apex predators relative to herbivores and other secondary consumers (Friedlander and Demartini 2002); resilience is enhanced by the variety of functional groups found in balanced reef communities, such as grazing fish populations that prepare or maintain substrate for coral recruitment and growth after disturbance (West and Salm 2003). Inclusion of these reefs in a National Marine Sanctuary may help to further protect them from sedimentation, contaminants, and overharvesting. In contrast, coral bleaching, predator outbreaks, disease, and invasive species are not as readily controlled as more conspicuous human activities such as construction, shipping, or fishing.

Resistance to mass coral bleaching may derive from intrinsic factors such as speciesspecific physiological tolerance (West and Salm 2003). Of the two genera, Porites and Pocillopora, that dominate or codominate in all habitats at FFS, Pocillopora is the more vulnerable to coral bleaching, which in 2002 most affected the three northernmost atolls in the NWHI (Pearl and Hermes, Midway, Kure) (Aeby et al. 2003, Kenyon et al. 2004b) with bleaching incidences as high as $96 \%$ (Kenyon et al. in press). Though bleaching was not detected at FFS during site-specific surveys, analysis of videotapes recorded during towed-diver surveys along the forereef and in the lagoon revealed pocilloporid bleaching incidences of 32 and $22 \%$, respectively, during that event (Kenyon et al. in press). In contrast, massive and encrusting Porites demonstrated low susceptibility to bleaching; their highest incidence of bleaching in any habitat at the three northernmost atolls was $18 \%$, and their maximum bleaching incidence at FFS was only $1.4 \%$ on the fore- reef. Porites compressa demonstrated moderate levels of susceptibility, with 31 and $16 \%$ of the surface area of dense thickets affected in the lagoon at Pearl and Hermes Atoll and FFS, respectively (Kenyon et al. in press). Numerous field studies indicate that acroporids are among the taxa most sensitive to bleaching (e.g., Hoegh-Guldberg and Salvat 1995, Marshall and Baird 2000), but Acropora was not observed to be affected by the relatively minor bleaching documented at FFS during the 2002 event in the NWHI. Although montiporids along with pocilloporids were highly susceptible to bleaching at the three northernmost atolls during the 2002 event, the current relative scarcity of Montipora colonies at FFS moderates the effect that future mass bleaching would have on the coral community overall. The differential responses of coral genera to bleaching in the NWHI coupled with the predominance of massive and encrusting Porites thus renders the reefs of FFS moderately resistant to the effects of bleaching with respect to structural architecture. In contrast, the vulnerability of Pocillopora and Acropora to bleaching, coupled with their substantial contribution to the coral fauna in localized areas, would likely result in concentrated areas of ecological disturbance should a severe mass-bleaching event affect this atoll.

In assessing the vulnerability of reefs to stressors, the concept of "resistance" (West and Salm 2003) as the ability to selectively withstand damage can be usefully broadened to additional sources of coral mortality. The preference of the corallivorous sea star Acanthaster planci for colonies of Pocillopora meandrina as prey, even when far more abundant Porites lobata and P. compressa are present (Chess et al. 1997), renders Pocillopora differentially vulnerable and Porites differentially resistant to potential crown-of-thorns outbreaks. Acroporids are also targeted as preferred prey in other regions where Acropora and Acanthaster co-occur (e.g., De'ath and Moran 1998). In situ observations of noncryptic Acanthaster during towed-diver surveys conducted throughout the NWHI between 2000 and 2003 indicated that their lowest frequency of occurrence was at FFS 
relative to other atolls (Timmers et al. 2004). The observed abundance of Acanthaster at FFS was low during all annual surveys; the largest number was observed in 2002, when 23 widely distributed Acanthaster were recorded in situ over towed-diver survey distances totaling $34.6 \mathrm{~km}$ (M. A. Timmers, unpubl. data). At all NWHI atolls (FFS, Pearl and Hermes, Midway, and Kure), Acanthaster was most abundant on the forereef (Timmers et al. 2004). These data suggest that areas of forereef at FFS with good representation of pocilloporids and acroporids (i.e., NE, E, and $\mathrm{S}$ sectors [Table 1]) might be most susceptible to any future outbreaks.

Although no data exist before 2000 from the NWHI with which to compare recent coral disease observations, the presence of tumors and lesions in Acropora cytherea at FFS (Work et al. 2002, Aeby 2004) raises concern about the exposure and vulnerability of this species' population to disease. Moreover, an outbreak in 2003 of a white band disease on Majuro Atoll (Republic of the Marshall Islands) affecting only tabulate acroporids, which resulted in 35\% mortality in A. cytherea over seven months (D. Jacobson, pers. comm.), highlights the low resistance of this species to a disease syndrome. Hawaiian acroporid populations are primarily restricted to the NWHI between Necker and Laysan, although isolated populations have been reported on Kaua'i; they are most diverse and abundant at FFS (Grigg et al. 1981, Maragos et al. 2004). Although little is known of the degree of connectivity among reefs of the Hawaiian Archipelago, the rarity of viable populations of Acropora in the main Hawaiian Islands and absence north of Laysan in the NWHI suggest limits to the scope or magnitude of larval dispersal, at least during spring and summer spawning windows (Kenyon 1992). Such limited dispersal also implies a reduced capacity for reseeding should local Acropora populations experience substantial declines. However, the presence of small $(<5$ $\mathrm{cm}$ ) Acropora colonies at FFS (Figure $6 a-c$ ) suggests some level of recruitment, particularly in the forereef zone. The current capacity of at least some coral populations at FFS for replenishment from reproductive propa- gules appears robust, based on the density of coral recruits calculated from two cohorts on recruitment plates after year-long deployments in the northern lagoon, where annual coral recruitment rates averaged $70.5 / \mathrm{m}^{2} / \mathrm{yr}$ (Dunlap and Kenyon 2004). These overall rates compare favorably with values reported from the main Hawaiian Islands (e.g., Fitzhardinge 1985, 1988, Brown 2004). Recruits from this single location at FFS, identified to the family level, belonged primarily to the Pocilloporidae $(92.7 \%, n=82)$; the Poritidae and Acroporidae represented only 4.9 and $2.4 \%$ of the recruits, respectively (M. Dunlap, unpubl. data). The disproportionately high representation of pocilloporids on recruitment plates compared with their moderate density in the lagoon (Figure 4) suggests high fecundity but low postrecruitment survivorship of Pocillopora relative to other taxa in this habitat.

To date, alien species of algae, which could compete with reef corals, have not been documented at FFS, and native algal species that have manifested invasive properties elsewhere are not problematic in their indigenous habitats at FFS (Vroom et al. in press). Two nonindigenous species of invertebrates, the hydroid Pennaria disticha and the barnacle Balanus reticulatus, have been reported as rare from the seawall and on reefs near Tern Island in the northern part of the lagoon at FFS. Although not currently known to have adverse effects on the ecosystem, their presumed introduction as fouling organisms on ships' hulls suggests some unintentional consequences of human traffic (DeFelice et al. 2002).

Resource management is undergoing a shift of perspective from individual species or stocks to an approach in which multiple physical processes and biological components of the environment are seen as vital to ecosystem function. While managers and scientists struggle how to define and implement ecosystem-based management in a marine context (Brainard et al. 2004, Fluharty 2004), long-term monitoring efforts at FFS and elsewhere in the NWHI are attempting to link biotic with environmental data through oceanographic instruments that are currently 
in place. These include a CREWS (Coral Reef Early Warning System) buoy that records and telemeters data pertaining to seasurface temperature, salinity, wind speed and direction, air temperature, barometric pressure, ultraviolet-B, and photosynthetically active radiation, and four subsurface seasurface temperature recorders deployed in shallow $(2-4 \mathrm{~m})$ locations throughout the atoll. The georeferenced, descriptive parameters presented in this study provide a baseline for future monitoring surveys to evaluate changes in the composition and size structure of the FFS coral community. Bak and Meesters (1999) predicted that habitat degradation through local effects of increased sedimentation, turbidity, and nutrient loads as well as through global change involving decrease in ocean calcium carbonate saturation will result in size distributions becoming increasingly left-skewed, with large colonies becoming more dominant in populations. This result is an expected outcome of reduced recruitment and increased mortality of small colonies. Though not addressed by Bak and Meesters (1999), the preference of Acanthaster planci for small ( $<5 \mathrm{~cm}$ diameter) pocilloporid colonies (Chess et al. 1997) would similarly result in a size-class distribution with a reduced number of individuals in the smaller size classes. Shifts in population parameters for each genus in each habitat must therefore be interpreted within the context of other ecological variables. Future surveys along specific tow tracks and at 12 longterm monitoring sites established in 2003 will yield a data time series from which percentage cover, density, and size-class distributions can be monitored for scleractinian corals at FFS, and their population dynamics, including response to local and global change, can be better understood.

\section{ACKNOWLEDGMENTS}

We thank the officers and crew of the NOAA ship Townsend Cromwell and the charter vessel Rapture for logistic support and field assistance. Rusty Brainard and Joe Chojnacki assisted in collection of towed-diver survey data; Kimberly Peyton, J. Kanekoa Kukea-
Schultz, Karla McDermid, and Brooke Stuercke assisted in collection of photoquadrat data; D. Potts assisted in collection of coral size-class data. Molly Timmers prepared Figure 2. Permission to work in the NWHI was granted by the Pacific Remote Islands Wildlife Refuge Complex, U.S. Fish and Wildlife Service, Department of the Interior, and the State of Hawai'i Department of Land and Natural Resources.

\section{Literature Cited}

Aeby, G. S. 2004. Baseline levels of coral disease in the Northwestern Hawaiian Islands. Abstract. In Northwestern Hawaiian Islands 3rd Scientific Symposium, 2-4 November 2004. NOAA National Marine Fisheries Service Pacific Islands Fisheries Science Center, Honolulu.

Aeby, G. S., J. C. Kenyon, J. E. Maragos, and D. C. Potts. 2003. First record of mass coral bleaching in the Northwestern Hawaiian Islands. Coral Reefs 22:256.

Amerson, A. B. 1971. The natural history of French Frigate Shoals, Northwestern Hawaiian Islands. Atoll Res. Bull. 150:1-383.

Bailey-Brock, J., R. Brock, and A. Kam. 1994. Coral growth on a sunken vessel serving as an artificial reef in Hawaii. Bull. Mar. Sci. 55:1326.

Bak, R. P. M., and E. H. Meesters. 1998. Coral population structure: The hidden information of colony size-frequency distributions. Mar. Ecol. Prog. Ser. 162:301306.

- 1999. Population structure as a response of coral communities to global change. Am. Zool. 39:56-65.

Bellwood, D. R., T. P. Hughes, C. Folke, and M. Nyström. 2004. Confronting the coral reef crisis. Nature (Lond.) 249:827-833.

Birkeland, C. 1999. Emphasis on colony size distributions in coral-reef surveys. Pages 65-72 in J. E. Maragos and R. GroberDunsmore, eds. Proceedings, Hawai' $\mathrm{i}$ Coral Reef Monitoring Workshop, 9-11 June 1998, Honolulu, Hawai'i. East-West Center and Hawai'i Department of Land and Natural Resources, Honolulu.

Brainard, R., G. Aeby, J. Chojnacki, E. De- 
martini, M. Dunlap, S. Ferguson, J. Firing, A. Friedlander, S. Godwin, J. Gove, R. Hoeke, S. Holzwarth, F. Kosaki, E. Keenan, J. Kenyon, M. Lammers, J. Maragos, J. Miller, K. Page, J. Rooney, M. Timmers, P. Vroom, C. Wilkinson, K. Wong, and B. Zgliczynski. 2004. Ecosystem science to support ecosystem-based management of the Northwestern Hawaiian Islands. Abstract. Page 67 in Northwestern Hawaiian Islands 3rd Scientific Symposium, 2-4 November 2004. NOAA National Marine Fisheries Service Pacific Islands Fisheries Science Center, Honolulu.

Brown, E. K. 2004. Reef coral populations: Spatial and temporal differences observed at six reefs off West Maui. Ph.D. diss., University of Hawai'i at Mānoa, Honolulu.

Chess, J. R., E. S. Hobson, and D. F. Howard. 1997. Interactions between Acanthaster planci (Echinodermata, Asteroidea) and scleractinian corals at Kona, Hawai'i. Pac. Sci. 51:121-133.

De'ath, G., and P. J. Moran. 1998. Factors affecting the behaviour of crown-of-thorns starfish (Acanthaster planci L.) on the Great Barrier Reef: 2. Feeding preferences. J. Exp. Mar. Biol. Ecol. 220:107-126.

DeFelice, R., D. Minton, and S. Godwin. 2002. Records of shallow-water marine invertebrates from French Frigate Shoals, Northwestern Hawaiian Islands, with a note on nonindigenous species. Bishop Mus. Tech. Rep. 23.

Dollar, S. J. 1982. Wave stress and coral community structure in Hawaii. Coral Reefs 1(2): 71-81.

Dollar, S. J., and R. W. Grigg. 1981. Impact of a kaolin clay spill on a coral reef in Hawaii. Mar. Biol. (Berl.) 65 (3): 269-276.

Dunlap, M., and J. Kenyon. 2004. Coral recruits to settlement plates at six Northwestern Hawaiian Islands. Abstract. Page 66 in Northwestern Hawaiian Islands 3rd Scientific Symposium, 2-4 November 2004. NOAA National Marine Fisheries Service Pacific Islands Fisheries Science Center, Honolulu.

Fitzhardinge, R. C. 1985. Spatial and temporal variability in coral recruitment in Ka- neohe Bay (Oahu). Proc. 5th Int. Coral Reef Symp., Tahiti 4:373-378.

- 1988. Coral recruitment: The importance of interspecific differences in juvenile growth and mortality. Proc. 6th Int. Coral Reef Symp., Townsville 2:673678.

Fluharty, D. 2004. Toward ecosystem-based management: What can the NWHI contribute? Abstract. Page 64 in Northwestern Hawaiian Islands 3rd Scientific Symposium, 2-4 November 2004. NOAA National Marine Fisheries Service Pacific Islands Fisheries Science Center, Honolulu.

Friedlander, A. M., and E. E. Demartini. 2002. Contrasts in density, size, and biomass of reef fishes between the Northwestern and main Hawaiian Islands: The effects of fishing down apex predators. Mar. Ecol. Prog. Ser. 230:253-264.

Gardner, T. A., I. M. Côte, J. A. Gill, A. Grant, and A. R. Watkinson. 2003. Longterm region-wide declines in Caribbean corals. Science (Washington, D.C.) 301: 958-960.

Grigg, R. W. 1983. Community structure, succession and development of coral reefs in Hawaii. Mar. Ecol. Prog. Ser. 11:1-14.

Grigg, R. W., and S. J. Dollar. 1980. The status of reef studies in the Hawaiian Archipelago. Pages 100-120 in R. W. Grigg and R. T. Pfund, eds. Proceedings of the Symposium on the Status of Resource Investigations in the Northwestern Hawaiian Islands. University of Hawai'i Sea Grant College Program Report, UNIHISEAGRANT-MR-80-04. Honolulu.

Grigg, R. W., and K. Y. Tanoue, eds. 1984. Proceedings of the Symposium on the Resource Investigations in the Northwestern Hawaiian Islands, 25-27 May 1983. University of Hawai'i, Honolulu, Hawaii. Sea Grant.

Grigg, R. W., J. Wells, and C. Wallace. 1981. Acropora in Hawaii, Part 1. History of the scientific record, systematics and ecology. Pac. Sci. 35:1-13.

Hoegh-Guldberg, O., and B. Salvat. 1995. Periodic mass bleaching of reef corals along the outer reef slope in Moorea, 
French Polynesia. Mar. Ecol. Prog. Ser. 121:181-190.

Houck, J. E. 1978. The potential of scleractinian corals in the study of marine environments. Ph.D. diss., University of Hawai' $\mathrm{i}$ at Mānoa, Honolulu.

Hughes, T. P., A. H. Baird, D. R. Bellwood, M. Card, S. R. Connolly, C. Folke, R. Grosberg, O. Hoegh-Guldberg, J. B. C. Jackson, J. Kleypas, J. M. Lough, P. Marshall, M. Nyström, S. R. Palumbi, J. M. Pandolfi, B. Rosen, and J. Roughgarden. 2003. Climate change, human impacts, and the resilience of coral reefs. Science (Washington, D.C.) 301:929-933.

Hunter, C. L. 1993. Genotypic variation and clonal structure in coral populations with different disturbance histories. Evolution 47 (4): 1213-1228.

Kenyon, J. C. 1992. Sexual reproduction in Hawaiian Acropora. Coral Reefs 11:3743.

Kenyon, J. C., R. E. Brainard, R. K. Hoeke, F. A. Parrish, and C. B. Wilkinson. 2004a. Towed-diver surveys, a method for mesoscale spatial assessment of benthic reef habitat: A case study at Midway Atoll in the Hawaiian Archipelago. Pages 348-356 in Proceedings, Coastal Zone Asia-Pacific Conference, Brisbane. Acacia Computing Services, Brisbane, Australia.

Kenyon, J. C., R. E. Brainard, G. S. Aeby, J. Chojnacki, M. J. Dunlap, and C. B. Wilkinson. 2004b. Mass coral bleaching on high latitude reefs in the Hawaiian Archipelago. Abstract. Page 135 in Abstracts, 10th International Coral Reef Symposium, Okinawa.

- In press. Mass coral bleaching on high latitude reefs in the Hawaiian Archipelago. Proceedings, 10th International Coral Reef Symposium, Okinawa.

Loya, Y. 1972. Community structure and species diversity of hermatypic corals at Eilat, Red Sea. Mar. Biol. (Berl.) 13:100123.

Maragos, J. E. 1972. A study of the ecology of Hawaiian reef corals. Ph.D. diss., University of Hawai'i at Mānoa, Honolulu.

. 1995. Revised checklist of extant shallow-water stony coral species from
Hawaii (Cnidaria: Anthozoa: Scleractinia). Bishop Mus. Occas. Pap. 42:54-55.

Maragos, J., and D. Gulko, eds. 2002. Coral reef ecosystems of the Northwestern Hawaiian Islands: Interim results emphasizing the 2000 surveys. U.S. Fish and Wildlife Service and Hawai'i Department of Land and Natural Resources, Honolulu.

Maragos, J. E., D. C. Potts, G. Aeby, D. Gulko, J. Kenyon, D. Siciliano, and D. VanRavenswaay. 2004. 2000-2002 Rapid Ecological Assessment of corals (Anthozoa) on shallow reefs of the Northwestern Hawaiian Islands. Part 1: Species and distribution. Pac. Sci. 58:211-230.

Marshall, P. A., and A. H. Baird. 2000. Bleaching of corals on the Great Barrier Reef: Differential susceptibilities among taxa. Coral Reefs 19:155-163.

McClanahan, T., N. Polunin, and T. Done. 2002. Ecological states and the resilience of coral reefs. Conserv. Ecol. 6 (2): 18. [online] http://www.consecol.org/vol6/ iss $2 / \operatorname{art} 18$.

Mundy, C. 1996. A quantitative survey of the corals of American Samoa. Report to Department of Marine and Wildlife Resources, American Samoa Government, Pago Pago.

NOAA (National Oceanic and Atmospheric Administration). 2003. Atlas of the shallow-water benthic habitats of the Northwestern Hawaiian Islands (draft). Silver Spring, Maryland.

Nyström, M., C. Folke, and F. Moberg. 2000. Coral reef disturbance and resilience in a human-dominated environment. Trends Ecol. Evol. 15 (10): 413-418.

Palumbi, S. R. 2005. Germ theory for ailing corals. Nature (Lond.) 434:713-715.

Pandolfi, J. M., R. H. Bradbury, E. Sala, T. P. Hughes, K. A. Bjorndal, R. G. Cooke, D. McArdle, L. McClenachan, M. J. H. Newman, G. Paredes, R. R. Warner, and J. B. C. Jackson. 2003. Global trajectories of the long-term decline of coral reef ecosystems. Science (Washington, D.C.) 301:955-958.

Pandolfi, J. M., J. B. C. Jackson, N. Baron, R. H. Bradbury, H. M. Guzman, T. P. Hughes, C. V. Kappel, F. Micheli, J. C. 
Ogden, H. P. Possingham, and E. Sala. 2005. Are U.S. coral reefs on the slippery slope to slime? Science (Washington, D.C.) 307:1725-1726.

Parrish, F. A., and J. J. Polovina. 1994. Habitat thresholds and bottlenecks in production of the spiny lobster (Panulirus marginatus) in the Northwestern Hawaiian Islands. Bull. Mar. Sci. 54 (1): 151-163.

Polacheck, T. 1978. The population biology of four common Hawaiian corals. M.S. thesis, University of Hawai'i at Mānoa, Honolulu.

Preskitt, L. B., P. S. Vroom, and C. M. Smith. 2004. A rapid ecological assessment (REA) quantitative survey method for benthic algae using photoquadrats with Scuba. Pac. Sci. 58:201-209.

Timmers, M. A., S. R. Holzwarth, and R. E. Brainard. 2004. Geographical distributions of Acanthaster planci from towed-diver sur- veys in the Northwestern Hawaiian Islands. Abstract. Page 68 in Northwestern Hawaiian Islands 3rd Scientific Symposium, 2-4 November 2004. NOAA National Marine Fisheries Service Pacific Islands Fisheries Science Center, Honolulu.

Vroom, P. S., K. N. Page, K. A. Peyton, and J. K. Kukea-Schultz. In press. Spatial heterogeneity of benthic community assemblages with an emphasis on reef algae at French Frigate Shoals, Northwestern Hawaiian Islands. Coral Reefs.

West, J. M., and R. V. Salm. 2003. Resistance and resilience to coral bleaching: Implications for coral reef conservation and management. Conserv. Biol. 17 (4): 956-967.

Work, T. M., S. L. Coles, and R. A. Rameyer. 2002. French Frigate Shoals reef health survey. Report to U.S. Fish and Wildlife Service, Honolulu. 
